\title{
PRE-FINISHING MILL MODERNIZATION ON THE STERLING STEEL ROD MILL*
}

Kermit Reins ${ }^{1}$

Neil S. Gow ${ }^{2}$

Wade P. Krejdovsky ${ }^{3}$

\begin{abstract}
The most recent modernization phase of the wire rod mill at Sterling Steel involved installation of a pre-finishing mill, using a Morgan Vee Mini-Block, a new water box and shear with utility systems and automation. The new mill configuration adds more stands to the mill for better drafting and is designed to improve finished product quality by providing a more uniform entry temperature, better control of the feed section into the No-Twist ${ }^{\circ}$ mill as well as enhanced surface quality. The new shear improves cut length accuracy as well as decreases the amount of trimming to reduce yield loss. This paper explains the changes made in the mill and the features of the new equipment and automation.
\end{abstract}

Keywords: Rod; Modernization; Quality; Productivity. 


\section{INTRODUCTION}

The origins of Sterling Steel can be traced back to the late 1800s and the production of barbed wire and other products much in demand for the developing western United States. Over the course of several decades and changes in organization, the operations eventually became the Northwestern Steel and Wire Company in Sterling, Illinois in 1936. The company steadily expanded capacity and improved steelmaking from the 1940s into the 1980s. In 1983, a single strand rod mill was installed by Morgan Construction Company, including a Morgan No-Twist ${ }^{\circledR}$ Mill finishing block, laying head and Morgan Stelmor ${ }^{\circledR}$ controlled cooling conveyor. This rod mill produced steadily over the next 15years with small upgrades during that time, the most significant of which were laying head modifications in 1997 to enable speeds of $100 \mathrm{~m} / \mathrm{s}$.

Following a shutdown in 2001, the rod mill was purchased in 2002 by Leggett \&Platt of Carthage, Missouri, and reopened in early 2003 as the Sterling Steel Company, LLC (SSC), to supply its wire drawing operations with wire rod. The new owner took a number of steps to modernize the operations, first to increase product quality and consistency with a a new Morgan Stelmor conveyor in 2002-2003, then changes in the finishing block area, and new water boxes with a temperature control system in 2008. In 2010, a modernization project was undertaken with Siemens Industry, Inc. (after Morgan Construction Company became part of Siemens) in order to improve the coil package, reduce maintenance and reduce delays on the finishing end of the rod mill, thereby increasing utilization and productivity. The project involved extending the Morgan Stelmor controlled cooling conveyor and replacing the coil reforming station to interface with a new vertical stem pallet coil handling system. The pallet coil handling system included a new-generation vertical compactor for consistent tying of the improved coil package. In addition, new automation was provided to optimize the operation of all new equipment components [1]. Other improvements in the line, such as the implementation of the SR Series ${ }^{\circledR}$ laying head pipe technology (see [2]), have enabled significant increases in productivity.

The latest phase of modernizations was started with a 2014 decision to invest in rolling line improvements, with improvements to be made by Primetals Technologies USA, LLC (after Siemens Industry, Inc. became part of a joint venture between Siemens and Mitsubishi). The main goal was to alleviate the loading in the existing roughing mill. The roughing mill was making high reductions which were resulting in motor overloads, high pass wear and difficulty in controlling section. The surface quality of the finished rod product was not at a consistently satisfactory level, caused by conditions in the roughing mill, Sterling believed. Also, the addition of a prefinishing mill (PFM) to the continuous mill, Sterling believed, could increase utilization by reducing the delays in the rod block for pass changes, and improve surface quality.

\section{MATERIAL AND METHODS}

\subsection{Products and Processing}

The product size range at Sterling is typically limited to $5.5 \mathrm{~mm}$ (7/32"), $6.35 \mathrm{~mm}$ (1/4") and $7.94 \mathrm{~mm}(5 / 16 ")$, for supply to internal wire drawing lines. To meet the needs of the wire drawing operations, the mill processes grades from AISI 1006 up through AISI 1080, with requirements for a high level of quality and consistency. 
Finished coils have nominal dimensions of $1,250 \mathrm{~mm}$ OD and $850 \mathrm{~mm}$ ID, with a nominal coil weight of $1,360 \mathrm{~kg}(3,000 \mathrm{lbs}$.). Yearly production with these three products is approximately 472,000 tonnes $(520,000$ tons).

\subsection{Layout and Process Description}

The Sterling rod mill reduces a $130 \mathrm{~mm}$ (5 1/8") square billet to $17.1 \mathrm{~mm}(0.67 ")$ in 14 stands. The stands in the roughing and intermediate mills are configured in a horizontal/vertical arrangement with roll diameters ranging from $565 \mathrm{~mm}$ (22") to 380 $\mathrm{mm}(15$ "), with a shear located after the sixth and 14th stands. Following stand 14, the pre-2014 mill arrangement had the section going "up the hill" to the finishing mill, consisting of a 10-stand Morgan No-Twist ${ }^{\circledR}$ Mill (NTM) of the "K" design. The sloped section contained a water box and led to a shear and side-looper before the NTM. The change in elevation in that part of the mill was $3.3 \mathrm{~m}$ (10'10") over a length of $17.7 \mathrm{~m}$ (58') for an approximate inclination angle of 10 degrees. Figure 1 shows a photo of this section of the mill before modifications and Figure 2 shows a 3-D model of the same.

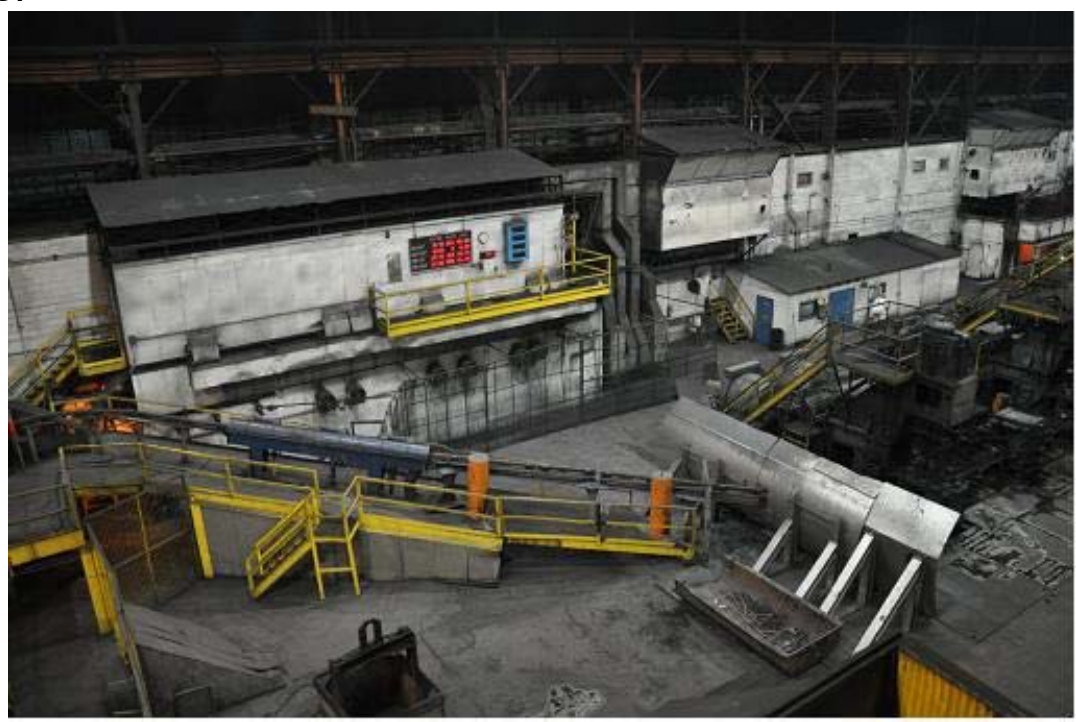

Figure 1. Area ahead of the No-Twist Mill before modifications.

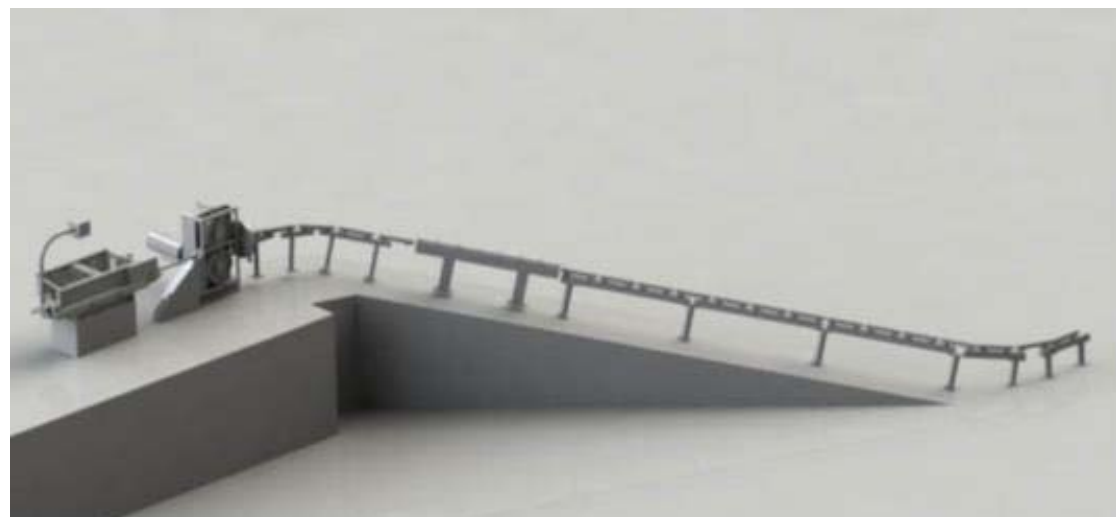

Figure 2. Model of area ahead of the No-Twist Mill before modifications.

SSC typically rolls $5.5 \mathrm{~mm}$ (7/32"), $6.35 \mathrm{~mm}(1 / 4$ "), and up to $12.7 \mathrm{~mm}(1 / 2$ ") at speeds of $100 \mathrm{~m} / \mathrm{s}(19,700 \mathrm{ft} / \mathrm{min})$ up to a maximum rolling rate of $85 \mathrm{t} / \mathrm{hr}(94 \mathrm{ton} / \mathrm{hr})$. 


\subsubsection{Previous Roll Pass Design}

In order to obtain the $17.1 \mathrm{~mm}$ feed section to roll $5.5 \mathrm{~mm}(7 / 32$ ") in the ten-stand NTM, there were some stands taking very high pass reductions. In the six-stand roughing mill, the average reduction per stand was $31.4 \%$ to obtain a $48.8 \mathrm{~mm}$ (1.92") round section at the stand $6 \mathrm{H}$ shear. Stand $3 \mathrm{H}$ alone performed a $43 \%$ reduction to make the square section from a slab. The reductions in this part of the mill were very high for a rolling mill desiring to roll high quality product, including high carbons. In addition to the high reductions, the passes were very full, so that without constant observation, the section could overfill and result in defects on the finished rod. The eight stands in the intermediate mill had an average reduction of $23 \%$ to produce the feed section for the $20 \%$ average reduction NTM. These relatively high reductions led to high pass wear, difficulty guiding, and ultimately a challenge to keep a consistent section into the NTM.

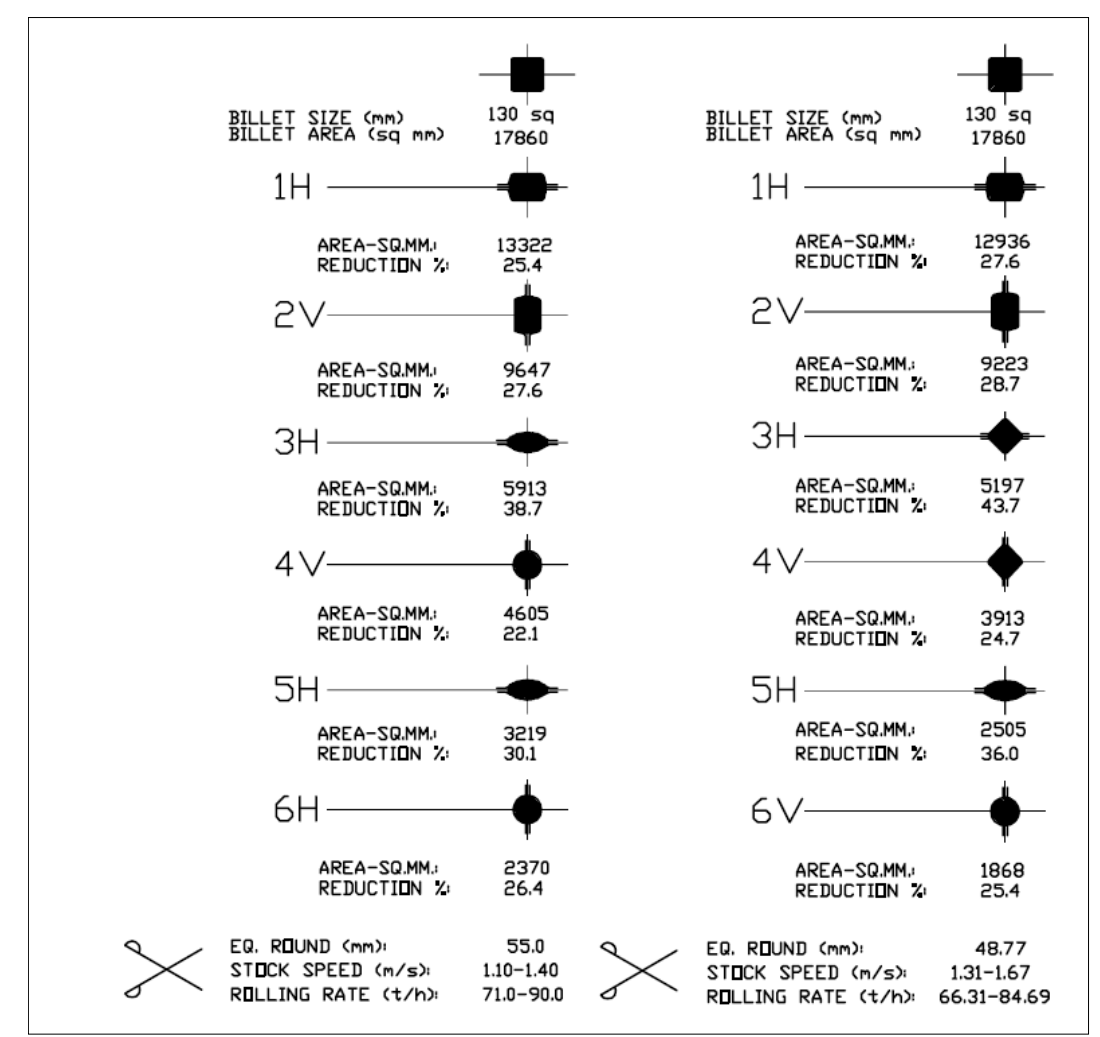

Figure 3. New roughing mill pass design (left) compared to previous design (right).

\subsubsection{New Pass Design}

The goal of modifying the pass design was to alleviate the high reduction sequences, remove square passes, and lower the filled width of the passes to manageable levels, all the while working within the limits of the existing equipment. With the new design, the six-stand roughing mill now makes a $55 \mathrm{~mm}$ round (2.16") with an average reduction of $28.5 \%$ (see Figure 3 ). The highest reduction sequence is once again at stand 3 , but the box-oval sequence is reduced from $43 \%$ to $38.7 \%$. From stand 3 throughout the rest of the mill, the progression is oval-round, after elimination of the diamond-square passes in stands 3 and 4 . Even though the section at stand $6 \mathrm{~V}$ has increased from a $48.8 \mathrm{~mm}$ round to a $55 \mathrm{~mm}$ round, the section at stand 14 is now $21 \mathrm{~mm}$ instead of $17.1 \mathrm{~mm}$. This is a $20.7 \%$ average reduction, down from $23 \%$. The final 12 stands (2 PFM plus 10 NTM) are $20 \%$ average reduction. The revised pass design for the intermediate mill is shown in Figure 4. 

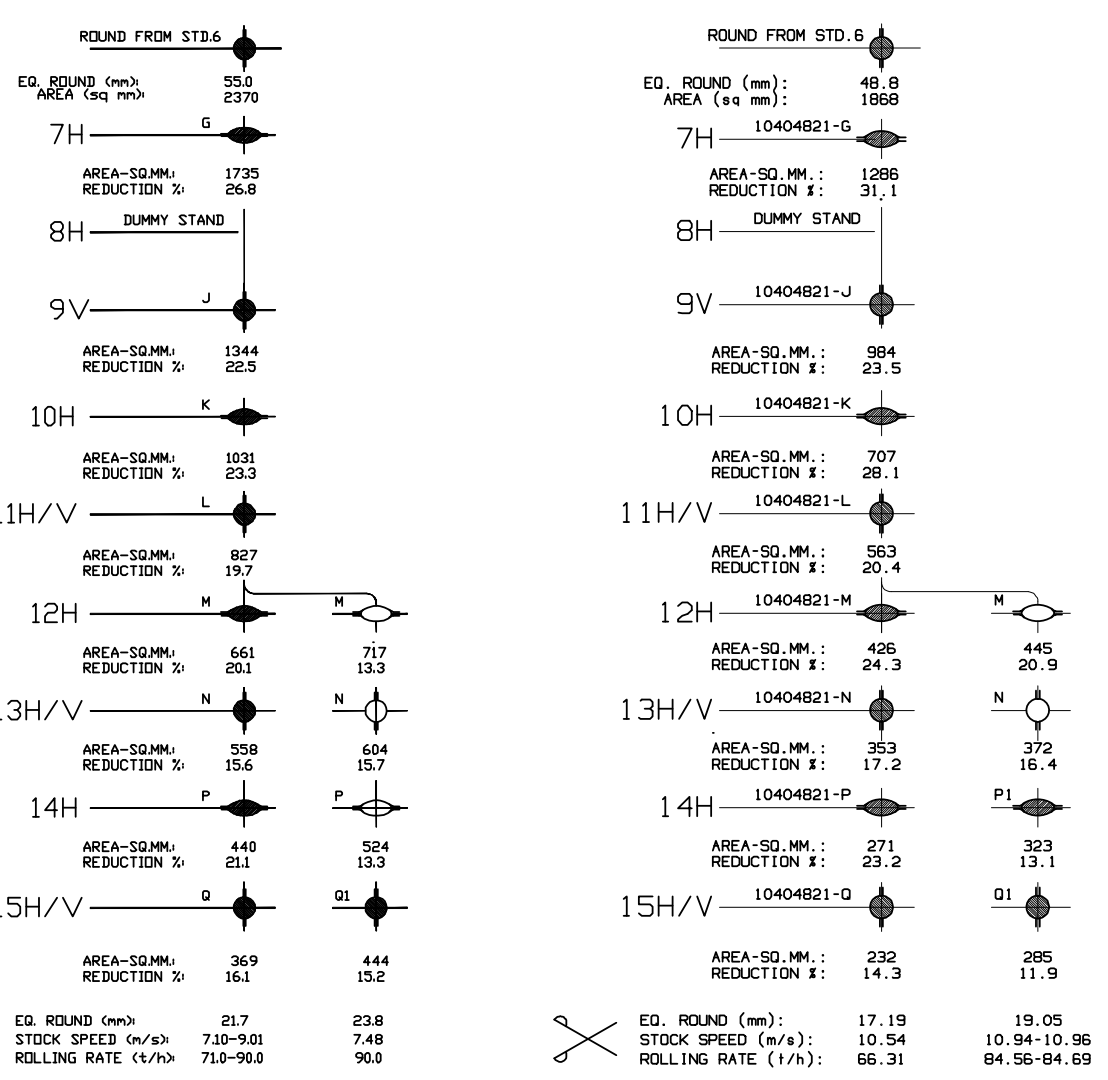

Figure 4. New intermediate mill pass design (left) compared to previous design (right).

\subsubsection{Motor Curves}

The pass design not only needs to consider the groove design for good flow of material with proper shape and quality, but also must work within the limits of the mechanical and electrical equipment. The torque and separating forces generated during rolling need to be within the capacities of each stand, roll neck, and gearing. In addition, the power required to roll must be within the available electrical power, and the speed (rpm) of the rolls must correlate to an available speed range of the motor, taking into account the maximum and minimum roll diameters and the overall motor-to-roll gear ratio.

When designing a roll pass sequence for an existing rolling mill, some investigation is required to understand the true capabilities of the equipment. The information on the motor and drive nameplates provides details, but does not tell the full story. At Sterling, the full electrical system had to be studied to determine how much actual power and torque was available for rolling, to account for other factors that affect the available power. For example, Stand 10 was believed to provide $540 \mathrm{~kW}(725 \mathrm{hp})$ at a base speed of $500 \mathrm{rpm}$, according to the motor nameplate. After investigation, the actual available rolling power was $468 \mathrm{~kW}(628 \mathrm{hp})$ at $600 \mathrm{rpm}$ base speed, due to limitations in cabling, the electrical drive and transformer capacity. With the actual available power known, Primetals Technologies was able to finalize the pass design to not only improve the quality of the product, but work within the limits of the existing equipment. Figure 5 shows the power envelope for this motor, with both the nameplate data and the actual data resulting from the study. 


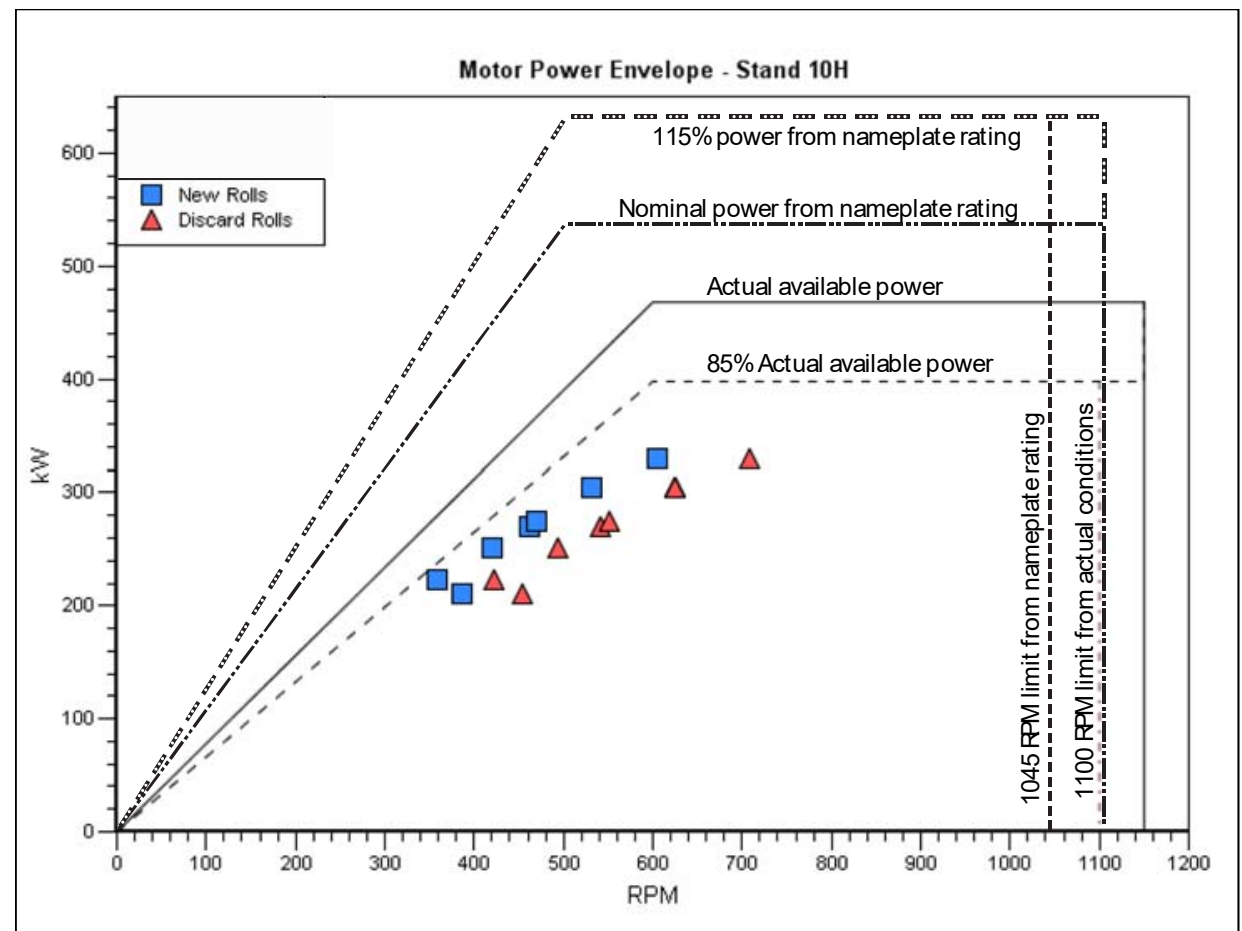

Figure 5. Stand $10 \mathrm{H}$ motor power envelope.

\subsection{New Equipment Description and Layout}

The latest modernization to the plant included the addition of a new PFM arrangement and a continuously rotating crop and divide shear before the existing NTM to replace the existing shear arrangement. In addition, the automation system was also updated.

\subsubsection{Pre-finishing Mill}

A Morgan Vee Mini-Block, such as shown in Figure 6, was chosen for the PFM stands and configured to produce the required process feed sections to the existing No-Twist mill to support a maximum product finishing speed of $105 \mathrm{~m} / \mathrm{s}(20,660$ $\mathrm{ft} / \mathrm{min})$ up to a rolling rate of $90.0 \mathrm{t} / \mathrm{hr}(99.2 \mathrm{tons} / \mathrm{hr})$. All process sections are rolled in the PFM utilizing an oval-round pass design sequence to minimize the investment in rolls, reduce operating cost and enable high productivity and high quality of the process sections With the section size from stand 14 increased as described above, allowing the pass reductions from stands 1 to 14 to be reduced, the PFM stands were used to produce the sections needed for the NTM (see Figure 7). 


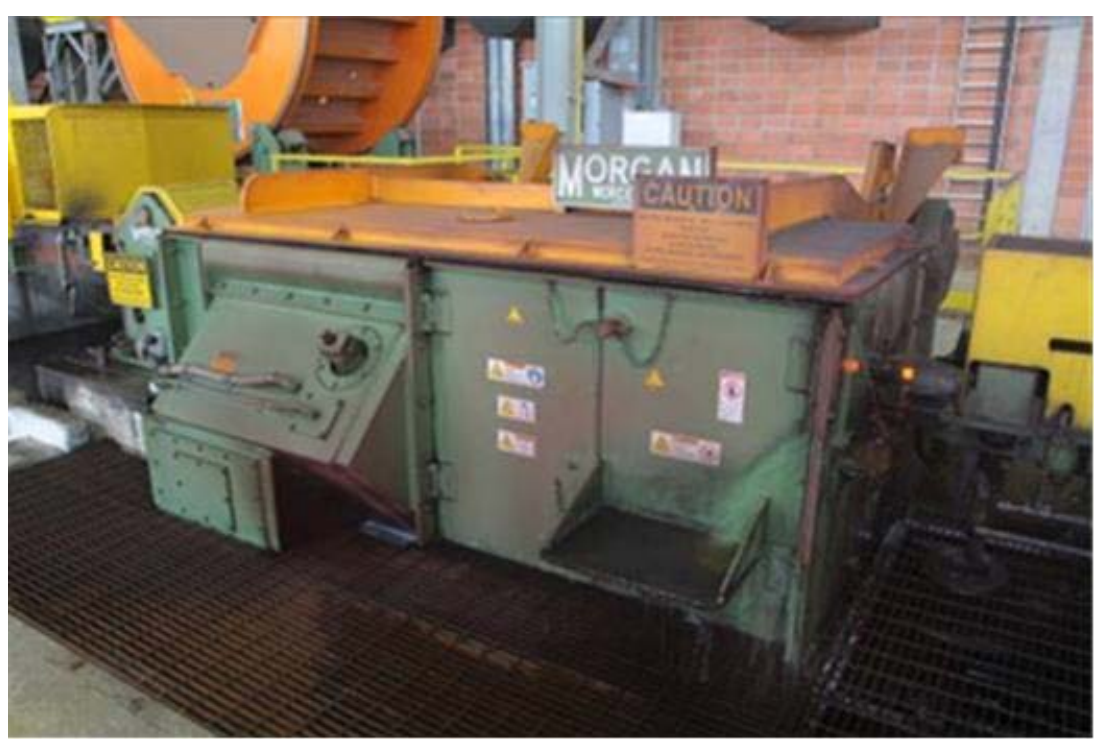

Figure 6. Morgan Vee Mini-Block in PFM arrangement.

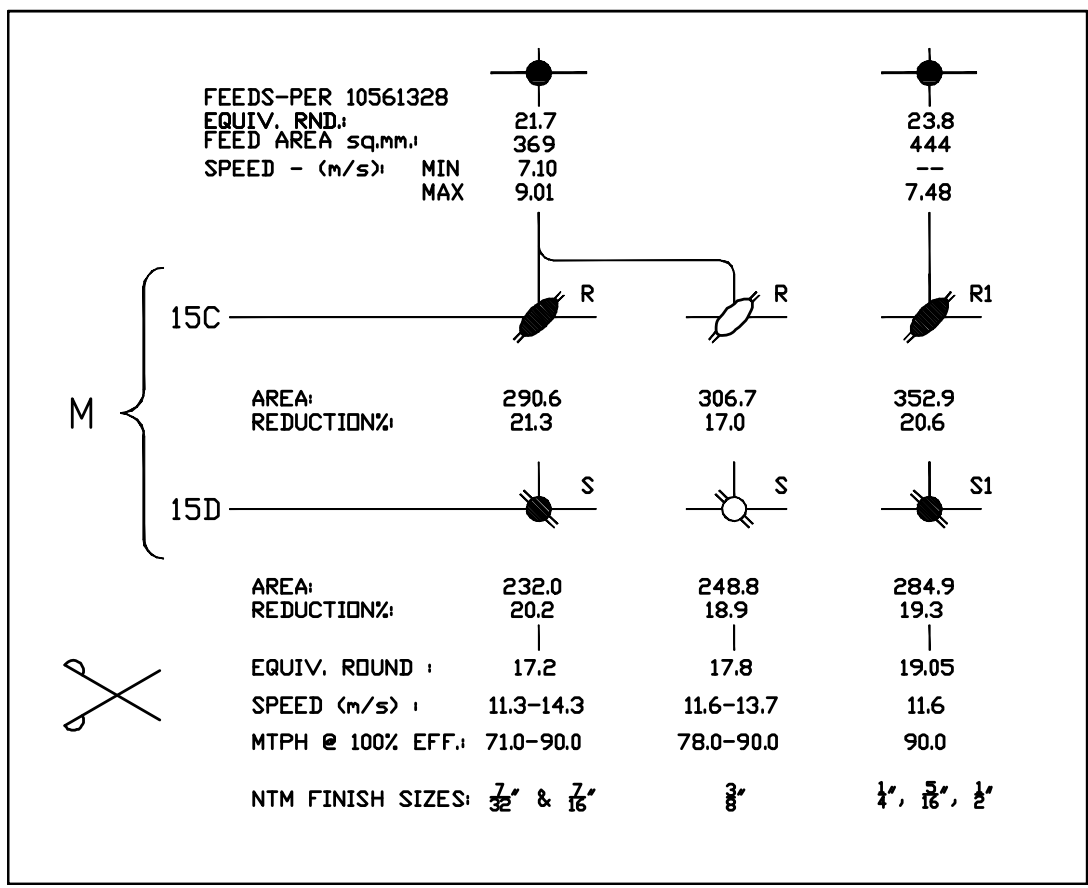

Figure 7. PFM roll pass design.

The block utilizes $230 \mathrm{~mm}$ cantilevered roll housings (see Figure 8 ) to provide the required separating force capacity and roll strength needed for the new process. Carbide rolls are used for increased pass life, thereby reducing downtime and increasing mill efficiency. The carbide rolls also provide superior surface quality over the life of the groove, further enhancing the quality of the finished product. The location of the new PFM was selected to allow installation of the new equipment during mill operation and for the installation of a second PFM in the future to accommodate either a larger starting billet size or further replacement of the conventional $\mathrm{H} / \mathrm{V}$ rolling stands. A new set of covered delivery troughs and a new water box before the NTM were also provided as part of the overall PFM arrangement. 


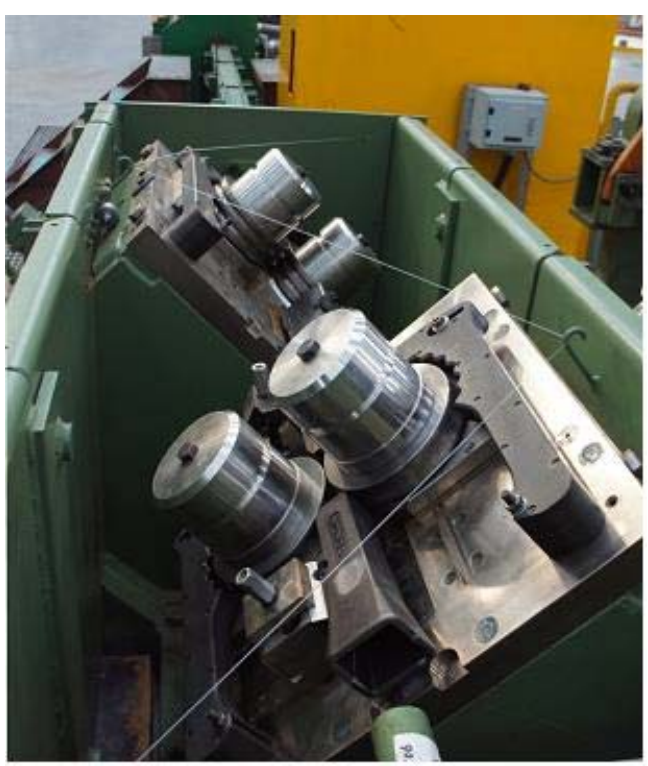

Figure 8. $230 \mathrm{~mm}$ roll housing of Morgan Vee Mini-Block.

\subsubsection{Crop and Divide Shear}

For the new shear arrangement before the existing NTM, an $800 \mathrm{~mm}$ (31.5 ") continuously rotating divide shear was selected (Figure 9). This four-bladed shear is used for front and tail end crop cuts as well as cobble cuts, all of which are collected in scrap buckets at mill floor level. A servo motor-operated switch located ahead of the shear controls the stock position for normal running (no cutting) or cutting for front ends, tail ends, or cobbles. As with the PFM, this arrangement is suitable for the potential expansion of the finished product size range in the future. This shear is designed to cut rounds up to $50 \mathrm{~mm}(2 ")$, but for Sterling, the motor was sized for $16.9 \mathrm{~mm}$ dia. $\left(224 \mathrm{~mm}^{2}, 0.35 \mathrm{in}^{2}\right)$ to $27 \mathrm{~mm}$ dia. $\left(573 \mathrm{~mm}^{2}, 0.89 \mathrm{in}^{2}\right)$.

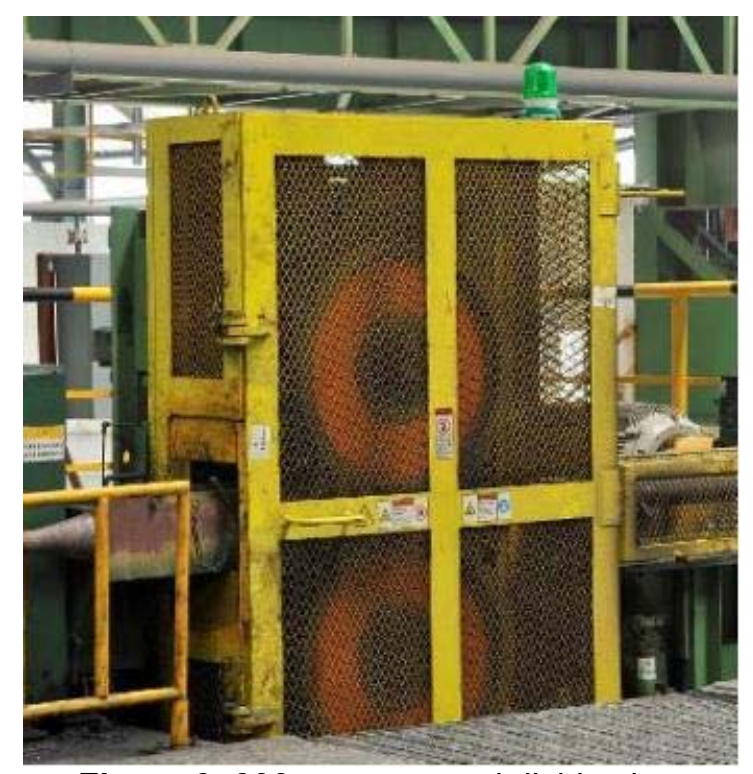

Figure 9. $800 \mathrm{~mm}$ crop and divide shear.

\subsubsection{Curved Troughs}

The new layout now has two 180 degree curved trough sections, with one of them also having an elevation change of $3.3 \mathrm{~m}$ (10 '10"). Water-cooled three-roll guide clusters were provided to give a rollerized path (see Figure 10). 


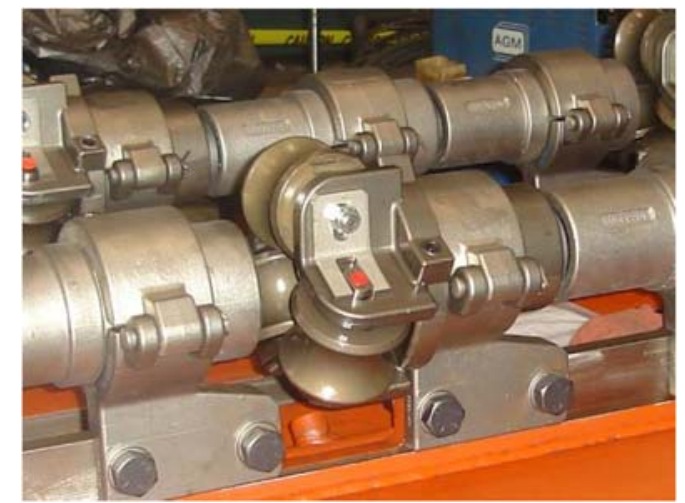

Figure 10a. Roller guides for curved trough.

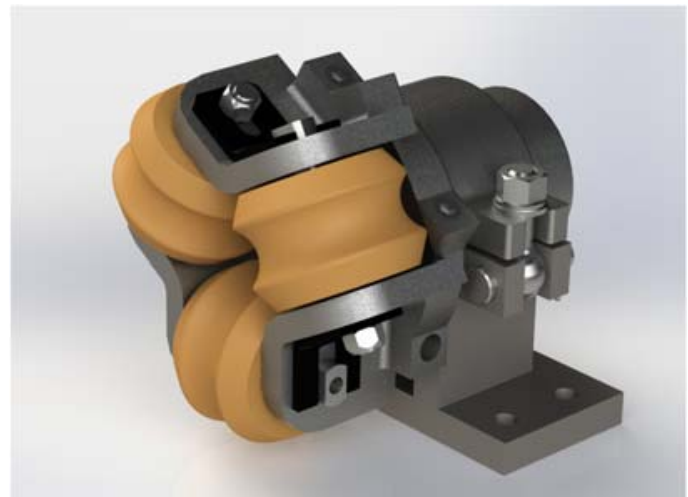

Figure 10b. Model of roller guide.

\subsubsection{Automation System Upgrade}

The existing mill automation system was upgraded with new PLC controllers to provide higher utilization as well as easier system maintenance, plus improved functionality for operators with a new Human Machine Interface (HMI) system. The scope of work included auxiliary mill control, shear control, addition of new DC control to the existing power section for the NTM, plus the addition of new DC drives to the existing laying head and pinch roll. New AC drives and motors were added for the PFM and new crop and divide shear. The system updates are designed to provide improved tension control throughout the mill and to minimize operator intervention during rolling.

The new, customizable HMI system provides the operations team with detailed diagnostic information as well as process information for quick access to current rolling conditions. In cases when a fault occurs, the system is capable of pinpointing the primary cause and location of the fault. A new recipe system gives the operators the ability to create and update standardized mill setups, which together with the HMI system, will enable faster mill start up times now that all required mill start signals displayed.

\subsection{Installation}

The new shear arrangement required consideration of several details, including relocating the centerline of the new shear upstream by approximately $900 \mathrm{~mm}(36$ ") from the centerline of the existing crop and divide shear. The new location was within the perimeter of the existing shear foundations. This allowed re-work of the existing foundations only versus complete new construction, which reduced the required downtime for installation. Furthermore, Sterling Steel was able to complete the entire installation with only 12 days of mill stoppage.

An overview of the new installation is shown in Figure 11 below and a model of the new equipment layout is shown in Figure 12, where some covers of the curved trough area have been removed to show the roller guides. 

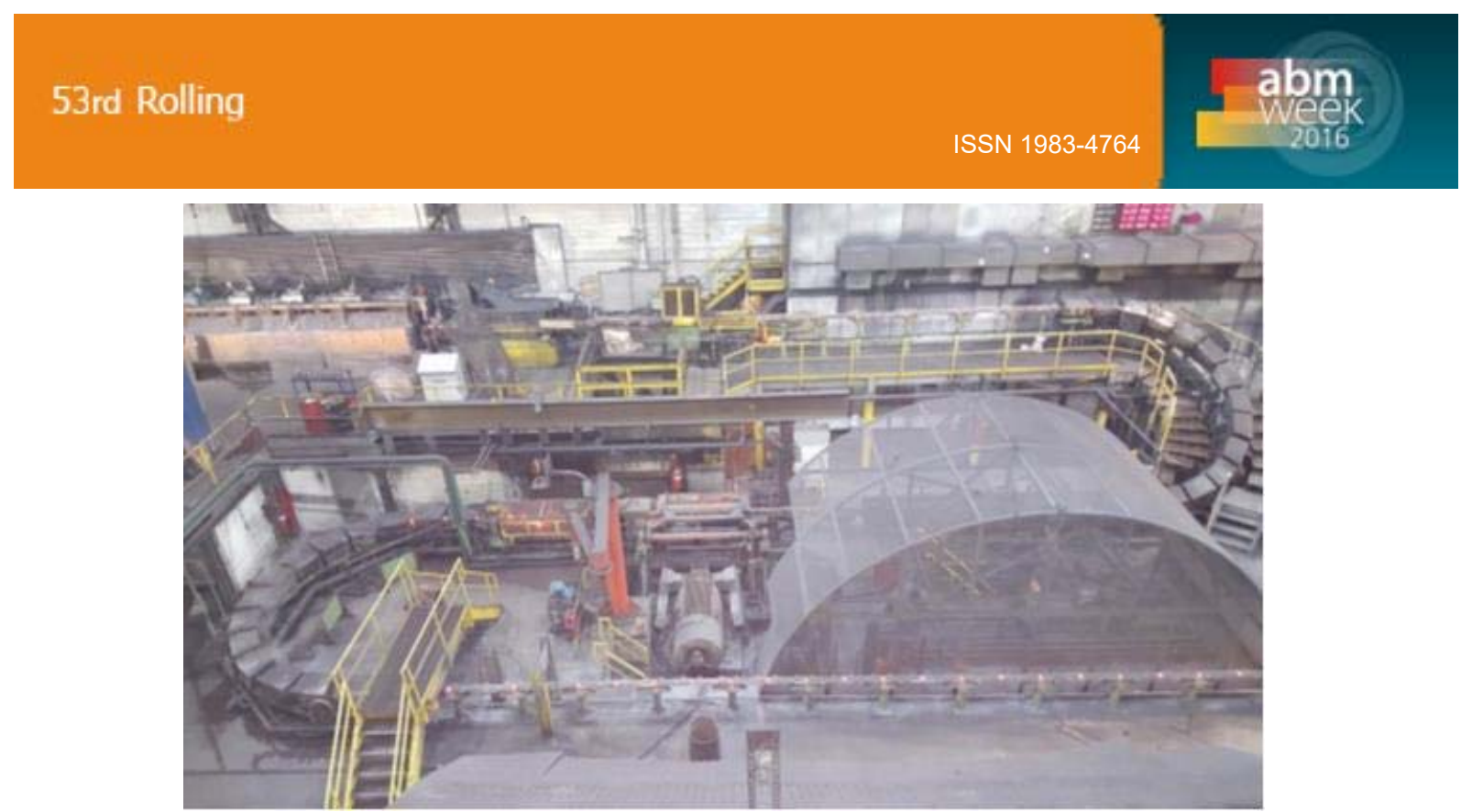

Figure 11. Pre-finishing mill area after modification.

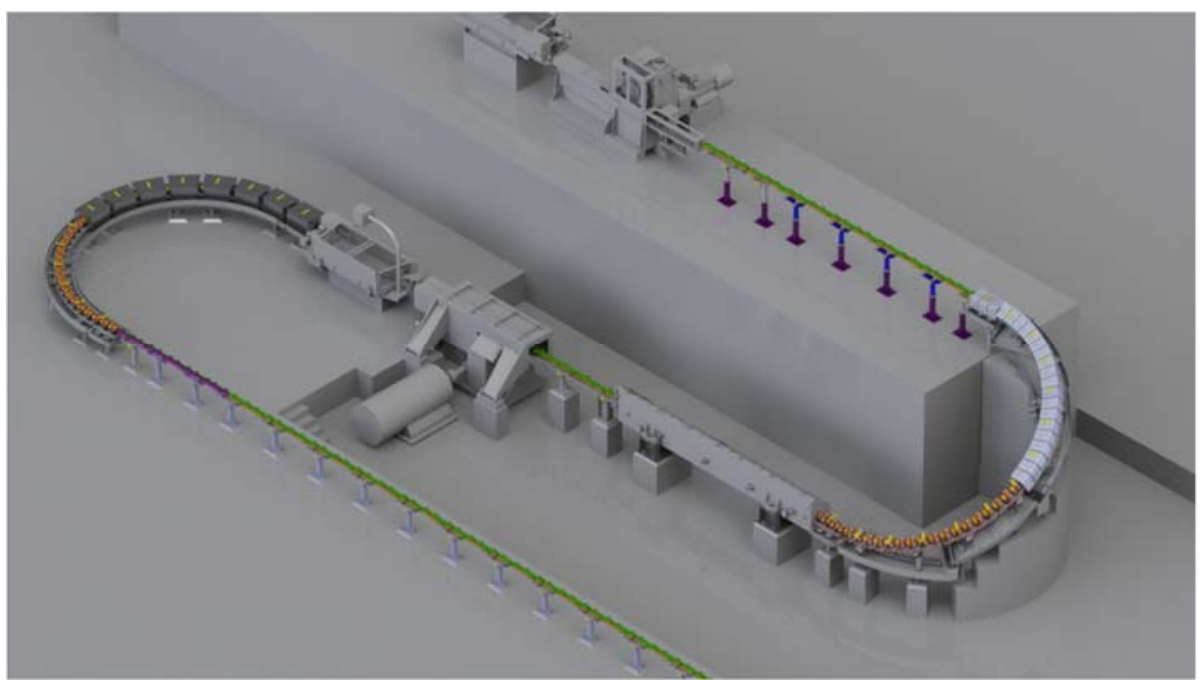

Figure 12. Model of pre-finishing mill area after modification.

\subsection{Future Expansion}

If Sterling ever increases billet size, there will be several required modifications to the mill, such as the addition of stands. The layout is configured to add a second PFM prior to the current one as well as preparing foundations for another shear. The extra two passes would maintain the overall reduction to roll a $165 \mathrm{~mm}(6.5$ ") square billet. In addition, other changes to motors and gearboxes may be needed.

Describe succinctly the equipment and procedures used, as the literature and the statistical methods and the corresponding literature, as the case demands.

\section{RESULTS AND DISCUSSION}

Despite the bar now making two 180 degree turns in the rolling line, its surface quality is better than it ever has been. The new pass design improved the surface of the bar, through elimination of the corners from the squares and the high reduction sequences. However, those improvements could be negated if the bar gets scratched or damaged traveling to the NTM. Therefore, to keep the bar clean and scratch-free, three-roll cluster guides were positioned around the horizontal 180 degree turn as well as the 180 degree turn with elevation change to the upper level. 


\subsection{Surface Quality}

The new roughing and intermediate mill pass design, using more carbide rolls, and the rollerized troughs have all contributed to an improvement of surface quality in the final rod. Laps, seams and rolled-in scale were more common on the rod surface prior to the modernization. See, for example, Figure 13. After the upgrade, these defects are detected much less frequently. Based on internal inspection criteria, the best ratings (flawless surface condition) were obtained on $56 \%$ of the rod before the upgrade, and after the upgrade the percentage rose to $73 \%$. Figure 14 shows an example of the improved surface quality.

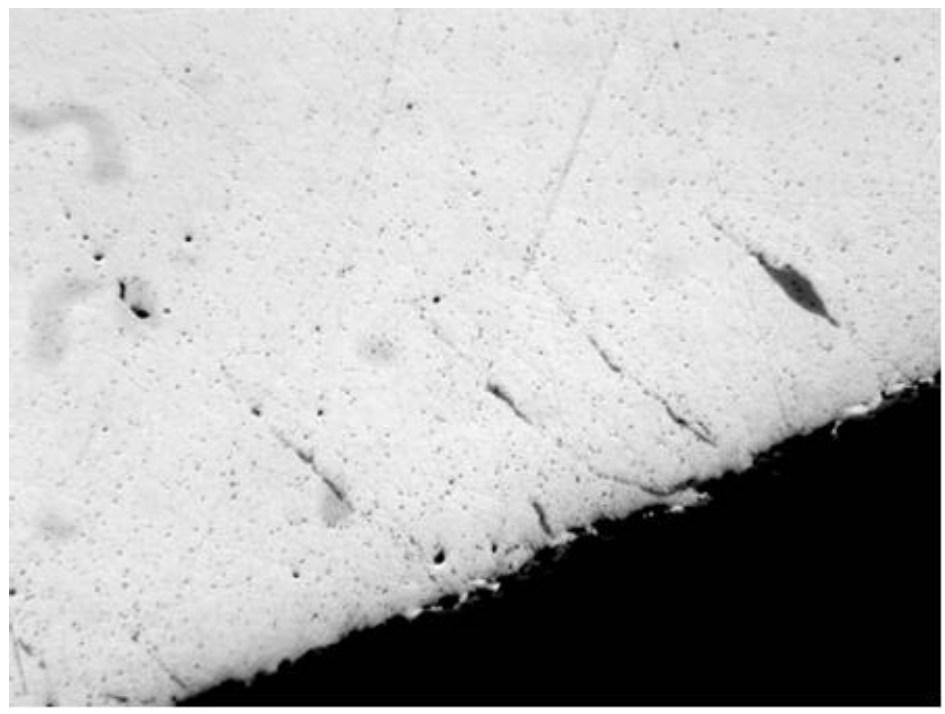

Figure 13. Example of pre-modification rod surface with seam defects and rolled-in scale (max. seam depth of $2 \%$ of wire rod diameter).

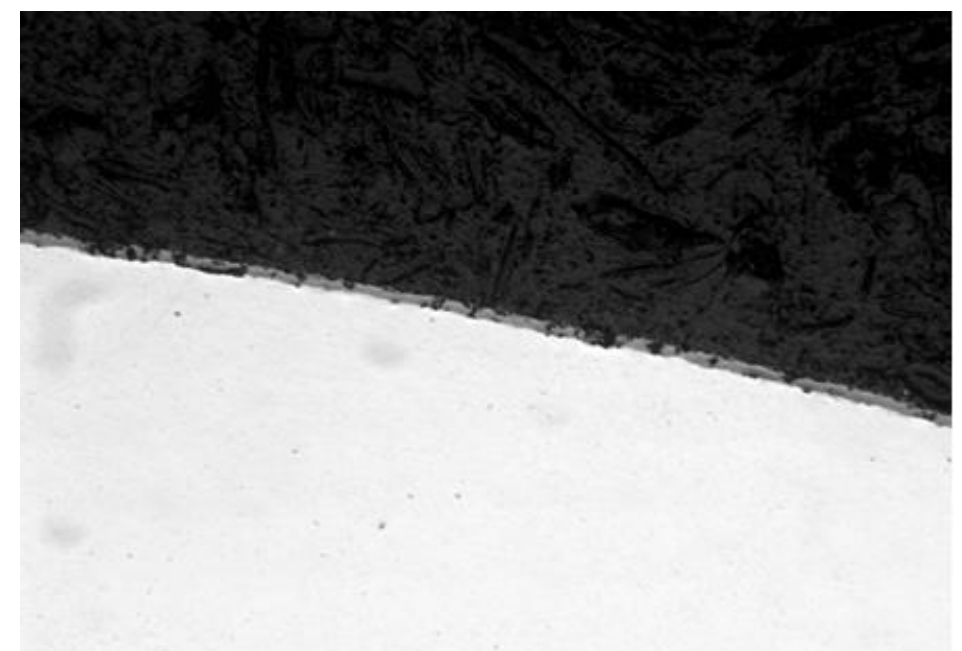

Figure 14. Example of post-modification rod surface with no defects. 
3.2 Pass Life and Downtime

The carbide rolls in the new PFM were expected to result in higher pass life at the end of the intermediate mill, but there have been improvements throughout the mill train due to the new pass design. Iron rolls are now used in just the first nine stands and tool steel rolls in the tenth stand. Carbide rolls are used in the last four bar mill stands as well as the rolls in the PFM and the rod block for a total of 16 stands using carbide rolls. These changes have increased pass life in some stands, improved section control in the rod block and created a marked improvement in surface quality. The improvements in pass design made in the roughing mill have increased roughing mill pass life in some stands by as much as $50 \%$. This increase in pass life allows the roughing mill to roll for an entire week before stopping to change passes. The pass changes can now be scheduled during the normal weekly maintenance outage. The new configuration has also reduced the motor loads in the previously overloaded roughing mill. Whereas broken rolls and broken teeth on gearing were sources of delays prior to the project, these have been dramatically reduced and some eliminated entirely.

\subsection{Shear}

The shear was tested to accurately take a $400 \mathrm{~mm}$ (16") head crop. Currently Sterling takes a $450 \mathrm{~mm}$ (18") head crop to present an appropriate head end into the NTM. This is an improvement over the previous shear that could reliably take a crop of $135 \mathrm{~mm}$ (53"). This saves $889 \mathrm{~mm}(35$ ") of material off of the front end of almost 350,000 coils which equates to almost $556 \mathrm{t}$ (613 ton) or $0.1 \%$ improvement in material yield annually.

\section{REFERENCES}

1 Reins, K., Spencer, S., Pietra-Santa, L., Rod Mill Finishing End Modernization at Sterling Steel, Proceedings, AISTech 2014, AIST, 2014.

2 Lashua, C, Kiefer, B., Recent Developments in Laying Head Technology for High Speed Rod Rolling Mills, Proceedings, AISTech 2014, AIST, 2014.

No-Twist, Stelmor and SR Series are registered trademarks of Primetals Technologies USA LLC. 